\title{
Efektivitas Dakwah Hadis dalam Media Sosial: Analisis atas Teori Framing Robert N. Entman
}

\author{
Perdana Putra Pangestu \\ Universitas Islam Negeri Sunan Kalijaga Yogyakarta \\ perdanaputrapangestu@gmail.com
}

\begin{abstract}
Hadis preaching is now meeting new challenges in its succession of implementation, one of which is its touch with courage-based social media. Apart from optimizing the propagation material that is disseminated, it has also become an interesting topic in discussions of the development of modern dakwah. In this case, content framing (framing) is deemed appropriate to package the dakwah content offered to the people in order to have authority on social media. However, the question that can be offered is how can the theoretical application of the framing concept work on da'wab content on social media? Departing from this formula, the author will elaborate the dakwah paradigm through content from several accounts on Instagram, based on the hadith as the preaching material. The author provides segmentation of the @ hadispedia and @pusatkajianhadis accounts as research objects using the theoretical synergy of Robert N. Entman's framing. This research is built on qualitative methods that are oriented towards the context of reality and data analysis of digital literature. The author will examine the focus of the problem with a descriptive-explorative orientation in order to obtain an optimal and comprehensive understanding. The argument from this research is that the concept of framing actualized on the preaching of hadith content, especially on @ hadispedia and @pusatkajianhadis accounts, can increase the effectiveness of the implementation of da'wah on social media.
\end{abstract}

Keywords: Effectiveness of Da'wah, Da'wah Hadith, Social Media, Framing

\begin{abstract}
Abstrak
Dakwah hadis kini seringkali menemui tantangan-tantangan baru dalam suksesi pelaksanaannya, salah satunya adalah singgungannya dengan media sosial berbasis daring. Selain pengoptimalan materi dakwah yang disebarkan, efektivitas juga menjadi sebuah topik menarik dalam perbincangan perkembangan dakwah modern. Dalam hal ini, pembingkaian konten (framing) dirasa tepat untuk mengemas muatan dakwah untuk ditawarkan kepada umat dalam rangka efektivitasnya di media sosial. Namun, pertanyaan yang sekiranya dapat ditawarkan adalah bagaimana aplikasi teoritis mengenai konsep framing dapat bekerja pada kontenkonten dakwah di media sosial? Berangkat dari rumusan tersebut, Penulis akan mengelaborasi paradigma dakwah melalui konten dari beberapa akun di Instagram, dengan basis hadis sebagai materi dakwahnya. Penulis memberikan segmentasi terhadapakun@hadispediadan@pusatkajianhadis sebagai objek penelitian
\end{abstract}


dengan menggunakan sinergi teroritis framing Robert N. Entman. Penelitian ini dibangun atas metode kualitatif yang berorientasi pada pengamatan konteks realita dan analisis literatur data digital. Penulis akan mengkaji fokus problem dengan orientasi secara deskriptif-eksploratif dengan tujuan untuk memperoleh pemahaman yang optimal dan komperehensif. Argumentasi yang didapat dari penelitian ini adalah konsep framing yang diaktualisasikan pada konten-konten dakwah hadis, utamanya pada akun@hadispediadan@pusatkajianhadis, dapat berperan dalam efektivitas pelaksanaan dakwah di media sosial.

Kata Kunci: Efektivitas Dakwah, Dakwah Hadis, Media Sosial, Framing

\section{Pendahuluan}

Penelitian hadis akhir-akhir ini seringkali hanya berkutat pada analisis historisitas teks maupun kajian pada literatur-literatur klasik. Belum banyak observasi penelitian yang secara konkrit menggali aspek-aspek dalam hadis dan singgungannnya dengan konteks masa kini, khususnya fenomena kemajuan teknologi dan media sosial. Perkembangan kajian hadis cenderung mengalami stagnansi pada pola operasionalnya sebagai suatu disiplin ilmu yang independen. Kecenderungan tersebut bermula dari paradigma bahwa hadis merupakan teks yang sulit dijangkau dan tidak bisa diintervensi dengan faktor kekinian. ${ }^{1}$ Namun disamping itu, masif pula dijumpai ruang-ruang digital yang sudah melibatkan instrumen agama, khususnya hadis, sebagai media untuk membuat serta menyampaikan suatu konten kepada publik. Sebut saja pada ranah dakwah yang tersebar dalam pelbagai varian media sosial (Instagram, Twitter, dsb.)

Media dakwah hadis berbasis daring kebanyakan dijumpai dengan wajah yang variatif, bisa dalam bentuk audio visual hingga hanya sebatas potongan foto yang berisi slogan dan petuah keagamaan. Hadis dalam hal ini sering dijadikan data kutipan dalam potongan-potongan foto yang di dalamnya memuat pesan, nasihat, argumen, dsb. dengan disertai gambar-gambar menarik. Realitas ini menjadi fenomena baru dalam pertemuan hadis dengan kemajuan teknologi masa kini, sehingga dakwah dan pembelajaran tentang hadis menjadi lebih mudah diakses. Disamping itu, barometer media sosial berbasis daring sebagai alat untuk menyebarkan khazanah keagamaan sangat efektif. Kecepatan menjadi salah satu indikasi yang menjadikan media daring dipilih sebagai bilik untuk menuangkan ide, gagasan, pengetahuan, dsb. kepada masyarakat. ${ }^{2}$

Gerbner dalam Mustika, menyatakan bahwa media sosial menjadi piranti sekunder dalam aktivitas sosialisasi suatu informasi. Kehadiran media sosial menjadi penting sebab alat-alat konvensional sebelumnya kini mulai terkikis dengan kemajuan fasilitas teknologi yang ada. Hingga saat ini belum ada agen lain dalam penyebaran informasi yang mampu menyaingi otoritas media sosial

${ }^{1}$ Kamarudin Kamarudin, "Dakwah Dan Problematika Studi Hadis," AlMishbah: Jurnal Ilmu Dakwah Dan Komunikasi 9, no. 1 (2013): 142.

${ }^{2}$ Asep Syamsul M. Romli, Jurnalistik Online: Panduan Mengelola Media Online (Nuansa Cendekia, 2018), 37. 
berbasis daring. Pengaruh yang diciptakan oleh media sosial pun sangat signifikan dalam upaya persuasif serta konstruktif dalam perbincangan opini kemasyarakatan secara kolektif, baik pada sisi kognisi, afeksi, ataupun konatifnya. ${ }^{3}$

Audiens dalam realitas media sosial menurut klasifikasi perkembangan teknologi komunikasi Abercombie \& Longhurst (1998) dalam Hapsari, dinyatakan sebagai audiens yang kompleks. Maksudnya, audiens tekonologi komunikasi saat ini telah memasuki era dimana beberapa dimensi informasi dapat diakses melalui satu waktu maupun satu piranti. Dibutuhkan peran media yang cerdik dalam mengambil atensi publik agar muatan konten yang tersaji laris dalam dunia informasi. Audiens/ pengguna media sosial tersebut selanjutnya disebut dengan diffusion audience. ${ }^{4}$ Sehingga dalam hal ini, dakwah hadis era kontemporer selayaknya dapat memahami situasi tersebut untuk menyongsong metode dakwah yang tepat sasaran dan efektif. Hal ini akan membawa dakwah keagamaan, khususnya hadis, dapat diterima masyarakat dengan cepat namun tetap dalam koridor otoritasnya sebagai salah satu nomenklatur suci.

Namun, dibalik suksesi dakwah dengan muatan hadis sebagai instrumen utamanya, pihak content creator harus memutar otak dalam rangka mengumpulkan massa untuk mau mengonsumsi suatu konten, yakni dengan dibaca. Sebab dalam kontak informasi yang terjadi di media sosial memungkinkan adanya immediacy, yaitu skala efektivitas yang terjadi dalam konten media sosial tanpa melewati jeda penerbitan sebagaimana dalam media konvensional non daring. Sehingga dampak kausal yang terjadi adalah bagaimana seorang content creator menjadikan konten yang akan dimuatnya, secara efektif menarik massa dan membentuk opini atau pengetahuan baru kepada masyarakat. ${ }^{5}$ Di samping itu, Penulis menyebut content creator juga sebagai da'i dalam hal ini, sebab da'i dalam diskursus dakwah adalah pihak yang menyampaikan informasi keagamaan yang bersifat persuasif. Content creator tidak boleh melupakan aspek keilmuan yang utuh terhadap hadis dalam dakwahnya. Karena pada masa ini, banyak pihak yang dipertanyakan kredibilitas dan otoritasnya, namun dengan bebas menyebar

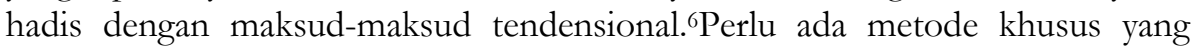
harus diterapkan dalam rangka penyesuaian content creator terhadap majemuknya pengguna media sosial, agar konten dakwah berisikan muatan hadis dapat sampai kepada masyarakat digital di media sosial. Salah satu metode dan pisau analisis yang harus digunakan adalah framing.

Framing secara sederhana bertolak dari analisis konstruksi realitas yang dilakukan oleh pihak penyusun konten. Tujuan framing tidak lain adalah untuk

${ }^{3}$ Rieka Mustika, “Analisis Framing Pemberitaan Media Online Mengenai Kasus Pedofilia Di Akun Facebook," Jurnal Penelitian Komunikasi 20, no. 2 (2017): 138.

"Twediana Budi Hapsari, "Audiens Framing: Peluang Baru Dalam Penelitian Audiens," Jurnal Aspikom 1, no. 6 (2017): 486.

$5 \mathrm{Jim}$ Foust, Online Journalism: Principles and Practices of News for the Web (Taylor \& Francis, 2017), 11.

'Kamarudin, "Dakwah Dan Problematika Studi Hadis,” 152. 
menujukkan tonjolan argumentasi agar lebih diingat, lebih bermakna dan lebih dipahami oleh konsumen suatu konten. ${ }^{7}$ Selain itu, framing mempermudah content creator dalam menyeleksi muatan produknya sesuai kebutuhan publik dengan analisa konteks yang ada/ sedang terjadi. Sehingga spesifikasi tema-tema tertentu akan secara efektif menuju kepada publik dengan pesan-pesan yang primer. ${ }^{8}$ Menyikapi hal ini, Penulis menyorot pelbagai media sosial berbasis daring yang berorientasi pada muatan dakwah, khususnya yang melibatkan hadis, menggunakan metode framing dalam memproduksi kontennya. Kemudian Penulis akan melakukan analisa mendalam terhadap fenomena tersebut dengan melakukan tinjauan teoritis mengenai metode framing dalam mengidentifikasi konten-konten dakwah tersebut. Adapun tujuan dalam penelitian ini adalah untuk mengetahui bagaimana content creator melakukan framing sebagai bentuk ajakan persuasif dalam menarik atensi publik. Penulis kemudian berharap uraian penelitian ini dapat berkontribusi pada pihak-pihak lain yang ingin melibatkan hadis dalam media dakwahnya dengan efektif dan efisien.

\section{Kerangka'Teori}

Menurut Entman, framing dapat ditilik dalam dua ranah makro. Dua ranah tersebut merupakan aspek yang bersinergi satu dengan yang lainnya, yaitu filterisasi isu dan mengemukakan variabel utama yang dapat memberikan value dan makna informatif. Filterisasi isu adalah tahap dilakukannya klasifikasi dan segmentasi cakupan kajian (informasi/ konten), sedangkan tahap kedua adalah melakukan penonjolan terhadap variabel-variabel tertentu yang dapat diingat oleh khalayak secara luas. ${ }^{9}$ lebih detail, Entman membedah aspek prosedural yang harus dilaksanakan dalam telaah framing terhadap suatu konten informasi. Pertama, define problems, yakni upaya dalam menyorot suatu isu sebagai suatu masalah. Dalam tahap utama ini (master frame) akan ada proses pemahaman oleh produsen informasi terhadap suatu perkara. Mengenai perkara kajian ini, pertanyaan yang dapat dinarasikan adalah bagaimana hadis dilihat sebagai objek permasalahan yang diangkat dalam konten dakwah di media sosial. Selain itu, pertanyaan yang lain adalah bagaimana pihak content creator merumuskan pandangannya terhadap hadis yang dikemukakan dalam kontennya.

Kedua, diagnose causes, yaitu tahap analisa terhadap penyebab suatu masalah. Analisa ini dapat dirumuskan sebagai "siapa" dan "apa" suatu problem berasal. Dalam konteks dakwah hadis, aspek penyebab masalah sekiranya bisa dirumuskan dalam dua kategori pertanyaan, yaitu apa konteks yang dipermasalahkan dalam hadis tersebut?; dan siapa yang mengemukakan permasalahan tersebut? Ketiga, makemoral judgements, yaitu memberikan stimulus

7DR Deddy Mulyana, Analisis Framing: Konstruksi, Ideologi, Dan Politik Media (Lkis Pelangi Aksara, 2002), 76-77.

${ }^{8}$ Kirk Hallahan, "Seven Models of Framing: Implications for Public Relations," Journal of Public Relations Research 11, no. 3 (1999): 224.

'Robert N. Entman, "Framing: Toward Clarification of a Fractured Paradigm," 1993, 52-53. 
argumentasi terhadap data sebelumya. Pada tahap ini, data yang telah dibingkai dan ditentukan penyebab keberadaannya, kemudian diberikan argumentasi yang membenarkan atau meruntuhkan data yang ada. Gagasan argumentatif tersebut selanjutnya melakukan penyesuaian terhadap konteks dan situasi familiar yang terjadi. Dalam hal ini, konten-konten dakwah hadis yang dijumpai akan direduksi secara majemuk dengan memberikan pernyataan serta fakta-fakta konkrit, guna mendapatkan definisi yang tepat terhadap konteks publik ketika konten tersebut dipublikasi. Keempat, treatment/ suggest recommendation, yaitu simpulan akhir berupa tawaran terhadap permasalahan yang sedang diangkat. Konteks dakwah hadis yang dikemukakan di media sosial harus dijumpai titik temunya dalam merespon maksud yang disampaikan oleh content creator. Hal ini akan mengarahkan pada sudut pandang apa yang sebenarnya ingin "didakwahkan" kepada netizen di media sosial.

Penelitian ini juga selanjutnya akan memperhatikan singgungan dengan realitas dakwah kontemporer yang mempunyai orientasi terhadap kemajuan teknologi informasi dan komunikasi. Analisis framing pada peristiwa dakwah hadis di media sosial sangat menarik untuk dikuak, sebab akan muncul stigma dominansi terhadap teks pada hadis yang ada. Putaran pembahasan mengenai analisis framing pun telah dilakukan oleh banyak peneliti sebelumnya. Kebanyakan dari penelitian tersebut adalah bentuk respon terhadap fenomena informasi pemberitaan di media konvensional maupun daring. Akan tetapi, elaborasi teks hadis dengan analisis framing kurang diperhatikan, sehingga belum muncul paradigma baru terhadap topik ini. Beberapa penelitian mengenai framing di piranti media informasi yakni oleh Mustika ${ }^{10}$, Atmadja ${ }^{11}$ dan Pratiwi. ${ }^{12}$ Sedangkan analisis terhadap dakwah masa kini juga banyak dibahas oleh peneliti sebelumnya, sebut saja dari Primasari ${ }^{13}$, Annisa ${ }^{14}$, Suriani ${ }^{15}$ dan Nurrahmi. ${ }^{16}$ Pelbagai hasil penelitian tersebut akan menjadi tinjauan bagi Penulis dalam pembahasan topik ini.

${ }^{10}$ Mustika, "Analisis Framing Pemberitaan Media Online Mengenai Kasus Pedofilia Di Akun Facebook.”

${ }^{11 X e n a ~ L e v i n a ~ A t m a d j a, ~ " A n a l i s i s ~ F r a m i n g ~ T e r h a d a p ~ P e m b e r i t a a n ~ S o s o k ~}$ Basuki Tjahaja Purnama (Ahok) Di Media Online,” Jumal E-Komunikasi 2, no. 1 (2014).

${ }^{12}$ Ardhina Pratiwi, "Konstruksi Realitas Dan Media Massa (Analisis Framing Pemberitaan LGBT Di Republika Dan BBC News Model Robert N. Entman)," Thaqafiyyat: Jurnal Bahasa, Peradaban Dan Informasi Islam 19, no. 1 (2018): 50-71.

${ }^{13}$ Winda Primasari and Yudha Asmara Dwi Aksa, "Framing Pesan Dakwah Di Media Sosial," Jurnal Komunikasi Islam 7, no. 1 (2017): 66-86.

${ }^{14}$ Nur Annisa, "Keefektifan Dakwah Melalui Media Sosial Di Masa Pandemi," 2020.

15Julis Suriani, "Komunikasi Dakwah Di Era Cyber," An-Nida' 42, no. 1 (2018): 30-51.

${ }^{16}$ Febri Nurrahmi and Puteri Farabuana, "Efektivitas Dakwah Melalui Instagram," Nyimak: Journal of Communication 4, no. 1 (2020): 1-16. 


\section{MetodePenelitian}

Penelitian ini dilakukan dengan metode kualitatif yang berorientasi pada pengamatan pada konteks realita dan analisis literatur data digital. Lebih spesifik, penelitian ini mempunyai model content analysis, yang menurut Barcus dalam Suriani merupakan sebuah analisis ilmiah mengenai isi dari suatu konten informasi. ${ }^{17}$ Penelitian ini akan disusun secara deskriptif-eksploratif untuk memberikan pemahaman yang komperehensif dan utuh terhadap dakwah hadis dalam media sosial. Sedangkan, sudut pandang teoritis yang dipilih Penulis adalah perspektif framing menurut Robert N. Entman, yakni dengan tahap define problems, diagnose causes, make moral judgement dan treatment/ suggest recommendation.

Dalam pengambilan data, Penulis akan mengamati fenomena dakwah hadis yang berada pada wadah media sosial, yakni Instagram. Penulis melakukan sortir terhadap akun-akun dakwah yang tercantum kata "hadis" pada titel akunnya. Penulis selanjutnya akan memaparkan corak makro dari konten yang disajikan dalam beranda masing-masing akun, kemudian mengambil masingmasing unggahan yang diperlukan untuk didalami melalui analilsis framing Entman. Akun-akun yang dimaksud adalah@hadispedia dan @ pusatkajianhadis. Segmentasi yang Penulis pilih akan memunculkan probabilitas yang fokus, riil dan tepat terhadap pembahasan dakwah hadis di media sosial.

\section{Hasil Penelitian (Research Result)}

\section{Akun@hadispedia}

Akun Instagram@hadispedia ${ }^{18}$ adalah salah satu media dakwah yang mempunyai segmentasi hadis dalam muatan konten yang disajikannya, hal ini dibuktikan dengan keterangan pada tagline akun tersebut, "\#AyoNgajiHadis; Ensiklopedia Hadis dan Perbincangannya". Akun@hadispedia mempunyai corak kecenderungan untuk memuat konten berupa pengajaran ulumul hadis dengan lintas isu pembahasan, seperti ilmu sanad, rijal al-badis, ma'ani al-hadis, sejarah, hingga kajian kitab-kitab hadis kanonik. Selain fokus terhadap cakupan ulumul hadis, akun@hadispedia juga aktif merespon fenomena-fenomena aktual sebagai konteks dalam latar belakang konten yang dimuat, seperti singgungannya dengan realitas sosial kemasyarakatan hingga singgungan dengan perkembangan teknologi masa kini.

Akun@hadispedia kental dengan formulasi framing dalam solekan tiap konten yang dimuatnya. Sebagaimana uraian definisi framing di atas, akun @hadispedia menyajikan tonjolan-tonjolan dalam isi dakwahnya yang memunculkan paradigma makna yang khusus dan mendalam. Hal ini secara realistis dapat menciptakan ketertarikan konsumen media sosial akibat dampak persuasif yang diselipkan pada desain dan tonjolan kontennya, salah satu konten

\footnotetext{
${ }^{17}$ Suriani, "Komunikasi Dakwah Di Era Cyber," 32.

18“\#AyoNgajiHadis's (@hadispedia) Instagram Profile • 317 Photos and Videos," accessed January 9, 2021, https://www.instagram.com/hadispedia/.
} 
yang dimaksud adalah unggahan pada 15 Desember 2020. ${ }^{19}$ Unggahan tersebut mempunyai muatan hadis dengan spesifikasi topik tentang menangis, hal ini tertera pada layout utama unggahan tersebut. Postingan ini erat kaitannya dengan penggunaan framing sebagai upaya memikat konsumen untuk sejenak membaca. Faktor pemikat tersebut terletak pada komposisi teks yang padat dan lugas. Selain itu, unggahan disertai pula dengan kalimat yang familiar dan stiker logo mata menangis yang seolah merepresentasikan isi unggahan tersebut. Berikut adalah tampilan dari unggahan yang dimaksud;
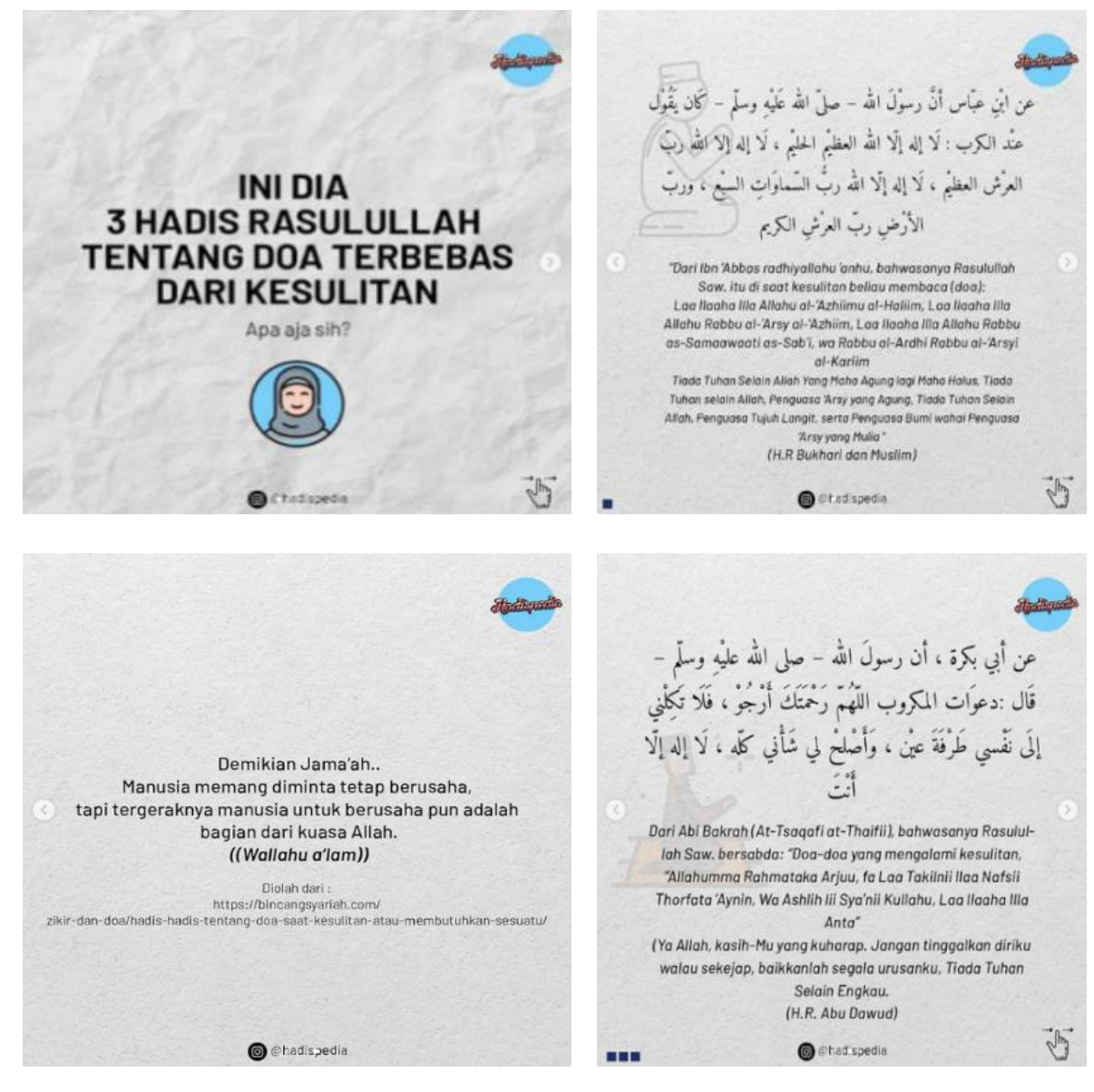

19“'AyoNgaji Hadis on Instagram: 'Diantara Ajaran Agama Islam Di Saat Kesulitan Atau Membutuhkan Sesuatu, Sebenarnya Adalah Kesadaran Kembali Bahwa Segala Yang Ditakdirkan...," accessed January 18, 2021, https://www.instagram.com/p/CHfIFvAD9ru/. 
74 J Junal Dakwah dan Komunikasi, Vol.6 No.1, 2021

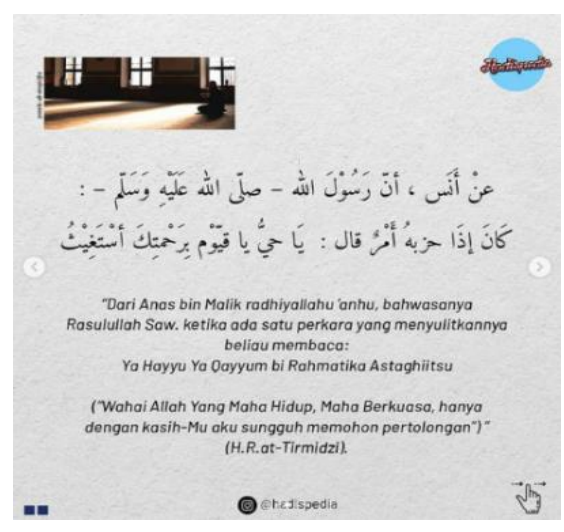

Menurut kaidah pertama yang ditetapkan Entman, yaitu define problems, maka dapat ditarik sebuah variabel awal bahwa content creator mengemas hadis-hadis tentang menangis yang disebabkan rasa takut kepada Allah. Informasi yang didapat yakni tercantum tiga hadis yang menjadi objek pemaparan dari topik yang diangkat. Hadis-hadis yang dikutip berasal dari tiga sumber berbeda, yakni Ittihaf al-Kiyaroh Imam Abu Bakar al-Bushiriy, Mustadrak Imam al-Hakim dan Musnad Imam Ahmad bin Hanbal. Kedua, dengan menggunakan diagnose causes, maka variabel kedua yang dapat diperoleh berasal dari caption (deskripsi singkat) unggahan tersebut. Caption pada postingan tersebut menjabarkan konteks sebagai "dalil" konten yang dimuat. Hadis tersebut disajikan oleh content creator dengan mengalokasikannya pada sebuah situasi dimana seorang muslim merasa sedih ketika sedang ditimpa ketakutan atau musibah dari Allah.

Ketiga, tahap analisis makemoral judgements pada unggahan tersebut memberikan sebuah putusan yang komperehensif. Maksudnya, variabelvariabel yang diperoleh sebelumnya telah diabsahkan dengan kutipan hadis secara tepat sasaran terhadap topik pembahasan yang sedang diangkat. Pada hadis pertama dan kedua mempunyai letak kesamaan substansi teks. Isi kedua hadis tersebut adalah terdapat anugerah bagi seorang muslim yang menangis sebab takut kepada Allah, yaitu matanya akan terjaga dari api neraka. Sedangkan hadis ketiga memberikan penekanan terhadap dialog mengenai aspek keberhasilan seorang muslim, yakni salah satunya dengan menangisi atas kesalahan/ kemaksiatan yang diperbuat. Keempat, pada tahap treatment/ suggest recommendation, benang merah terletak pada slide keempat yang memberikan penekanan terhadap poin dakwah yang disampaikan. Simpulan yang dimaksud adalah sebuah pernyataan bahwa tangisan yang didasarkan pada Allah, maka tangisan tersebut merupakan saksi atas anugerah-Nya kelak di akhirat. Jadi, nilai dakwah dari unggahan tersebut adalah janji Allah pada hamba-Nya yang menyesali perbuatan maksiatnya untuk dihindarkan dari siksa api neraka. 
Dari uraian analisis framing Entman pada konten akun @ hadispedia, dapat ditemukan pola dengan kecenderungan sama pada unggahan-unggahan yang lain. Kesamaan pola tersebut ditemui dalam cakupan topik yang bermacam-macam, sebut saja unggahan pada 6 Oktober 2020 dengan tajuk "Maksud Hadis Mencuri Dalam Shalat";20 18 November 2020 dengan tajuk "Pemimpin yang Menyusahkan Rakyatnya";21 dan yang lainnya. Pola strategi dakwah seperti yang dipraktikkan oleh akun@hadispedia membuahkan narasi yang menarik, tepat sasaran dan mendalam. Hal ini tidak lain dari prosedur alokasi bagian-bagian tertentu untuk ditonjolkan dalam sebuah unggahan yang dapat memberikan kesan retoris-persuasif pada konten dakwah hadis yang dimuat. ${ }^{22}$

\section{Akun@pusatkajianhadis}

Akun Instagram@pusatkajianhadis ${ }^{23}$ adalah salah satu akun yang dikelola oleh Pusat Kajian Hadis-Jakarta. Akun @pusatkajianhadis mempunyai segmentasi dakwah hadis dengan metode mengkaji dan menyebarluaskan hadis Nabi, dengan tujuan iut menjaga kemurnian ajaran agama Islam. Akun tersebut menyongsong bahasan hadis dengan topik-topik yang acak. Konten yang disajikan oleh akun@pusatkajiahadis lebih cenderung pada khazanah mengenai hadis-hadis yang bersinggungan dengan realitas sehari-hari, dengan menggunakan struktur pola judul topik, kutipan hadis dan terjemahannya. Berbeda halnya dengan akun@hadispedia yang lebih kompleks lingkup kajian yang diangkat, yangmana membahas sebagian besar tema-tema dalam perbincangan hadis, sekaligus merespon topik-topik aktual.

Ditinjau dari teori framing Entman, akun@pusatkajianhadis tidak berbeda jauh dengan akun@hadispedia dalam penyajian konten pada beranda medianya. Content creator menawarkan sebagian besar pesan dakwahnya pada potongan gambar dengan bingkai desain yang menarik dan komposisi teks yang padat. Seperti unggahan pada 15 Desember

20“\#AyoNgajiHadis on Instagram: 'Shalat Adalah Ibadah Yang Agung. Ia Menjadi Perintah Spesial Allah Swt. Yang Harus Diambil Nabi Saw. Langsung Ke Langit Melalui Peristiwa...,"” accessed January 11, 2021, https://www.instagram.com/p/CF_5jQXsRJ6/.

21 "\#AyoNgajiHadis on Instagram: 'Bener g Nih, Pemimpin Yang Nyusahin Rakyatnya Didoain Oleh Rasul Langsung? .. Yuk Kita Tela'ah Hadisnya, Bagaimana Sebenarnya Maksud Dari...,"' accessed January 11, 2021, https://www.instagram.com/p/CHuiWZCDkRV/.

22Mulyana, Analisis Framing: Konstruksi, Ideologi, Dan Politik. Media, 304.

23" Pusat Kajian Hadis (@pusatkajianhadis) - Instagram Photos and Videos," accessed January 11, 2021, https://www.instagram.com/pusatkajianhadis/. 
2020 dengan tajuk "Musibah Penghapus Dosa"24 yang merepresentasikan sebuah bingkaian pesan dakwah dengan cukup menarik. Berikut adalah tampilan unggahan yang dimaksud.

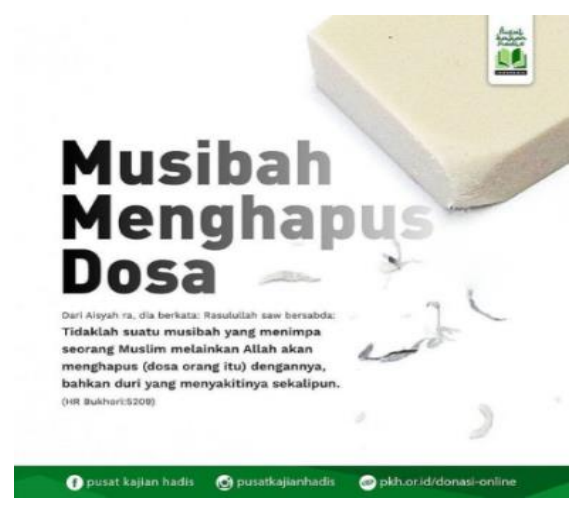

Apabila dikaji melalui analisis pertama, yakni define problems, maka variabel data yang dapat ditarik adalah content creator ingin menginformasikan hadis tentang kekuasaan Allah yang menghapuskan dosa hamba-Nya melalui sebuah musibah. Kedua, Penulis agak kesulitan dalam menentukan apa yang menjadi variabel data dari tahap diagnose causes.Sebab content creator dalam unggahan tersebut tidak secara gamblang mengutarakan sebab apa yang melatarbelakangi konteks hadis yang dinukil dapat bekerja. Hal ini juga sama dengan unggahan-unggahan akun @ pusatkajianhadis lainnya. Namun, Penulis setidaknya dapat menarik nilai konteks yang ingin disampaikan content creator, yakni situasi dimana seorang muslim sedang menerima musibah dan mengalami risau dengan musibah tersebut. Dalam hal ini hadis tersebut relevan pada situasi tersebut.

Ketiga, unggahan tersebut berangkat dari teks hadis riwayat Bukhari no. 5209 sebagai variabel data pada tahap analisis make moral judgments. Pada hadis tersebut diterangkan bahwa Allah menghapus dosa seorang muslim salah satuya adalah melalui didatangkannya musibah pada dirinya, bahkan hanya sekeder tertusuk duri. Keempat, pada tahap treatment/ suggest recommendation, simpulan yang dapat diambil dari unggahan tersebut terletak pada caption. Caption unggahan tersebut memberikan sebuah penegasan bahwa Allah pasti akan menghapus dosa dengan diberikannya musibah kepada manusia. Dengan demikian seorang hamba diminta untuk bersabar dan mendekatkan diri kepadaNya.

24“'Pusat Kajian Hadis on Instagram: ‘. . *Musibah Menghapus Dosa* ----

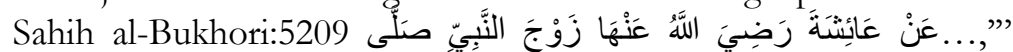
accessed January 11, 2021, https://www.instagram.com/p/CIOEHk2s-NQ/. 
Persamaan bentuk pembingkaian informasi pada akun (a)pusatkajianhadis dapat dijumpai dalam unggahan-unggahannya yang lain. Namun disamping itu, terdapat perbedaan yang cukup signifikan pada redaksi yang digunakan. Redaksi pesan dakwah pada akun @ hadispedia dijabarkan secara lengkap pada unggahannya, baik teks hadis, syarahnya hingga diskursus argumentatif dari hadis tersebut. Sedangkan dalam akun @pusatkajianhadis, redaksi dakwah hanya mencantumkan hadis dan terjemahannya, tidak disertai dengan penjabaran ataupun syarahnya. Hal ini membawa probabilitas pemahaman secara tekstual pada konten yang disajikan, sehingga kurang inklusif terhadap realitas konsumen yang beragam.

\section{Interpretasi pada Efektivitas Dakwah Masa Kini}

Setelah mengetahui hasil dari reduksi variabel data yang diperoleh melalui konten-konten dakwah hadis, perlu dilakukan pendalaman secara elaboratif pada sudut pandang dakwah masa kini. Sunarto dalam Primasari mengemukakan bahwa dunia dakwah kini sudah berkembang dengan definisi yang kompleks. Dakwah sudah merambah pada semua elemen kemasyarakatan dengan metode-metode terbarukan, hal ini secara definitif dapat disebut sebaagai dakwah dalam artian yang luas. ${ }^{25}$ Dakwah tidak hanya diselenggarakan melalui tabligh akbar yang tersegmentasi pada masjid dan tempat-tempat keagamaan saja, namun kini dapat dilakukan via medium yang bermacam-macam. Pelbagai media saat ini dapat digunakan untuk menginformasikan suatu pesan dan pengajaran tertentu dengan mudah, pembentukan identitas, serta mengkonstruksi self esteem. Fenomena baru ini tidak lagi asing, sebab dakwah yang sudah produktif pada ranah teknologi dapat mematahkan berbagai hambatanhambatan komunikasi yang selama ini ditemui di dakwah konvensional. Sehingga relasi antara dunia komunikasi dan dakwah tidak bisa dipisahkan secara parsial, melainkan harus dilakukan sinergi dan interaktif menjadi "Komunikasi Dakwah". ${ }^{26}$

Salah satu efektivitas yang disinggung dalam topik ini adalah pemangkasan waktu. Efektivitas dalam memperpendek durasi distribusi menjadi salah satu kelebihan dalam teknologi informasi. Sebab dalam realitanya, teknologi informasi masa kini telah menghapus batas geografis yangmana sebelumnya disebut dengan hambatan dakwah konvensional. Tentu ini sangat berperan pada intensitas materi dakwah yang masih

25Primasari and Aksa, "Framing Pesan Dakwah Di Media Sosial," 67-70.

${ }^{26}$ Faradillah Iqmar Omar et al., "Hubungan Penggunaan Media Sosial Dan Penerimaan Mesej Dakwah," in Proceeding of the 2nd International Conference on Management and Muamalah, 2015, 183. 
aktual apabila waktu terjadinya suatu perkara, berbanding lurus dengan distribusi informasi kepada masyarakat. ${ }^{27}$

Selain itu, dakwah di media sosial terbukti memberikan sumbangsih terhadap pembentukan pribadi muslim. Efektivitas dakwah di media sosial bisa diraih dengan memenuhi beberapa aspek yang menyangkut pribadi muslim itu sendiri, baik efek kognitif, afektif dan psikomotorik. ${ }^{28}$ Menurut Ibn Qayyim al-Jauziyah (w. $751 \mathrm{H}$ ) dalam Hefni merincikan tahapan dalam pembentukan pribadi muslim secara konstruktif dan progresif. Pertama adalah afkaar, yakni informasi atau ilmu yang diperoleh melalui berbagai varian media akan dikumpulkan secara simultan oleh seorang muslim. Hal ini dilakukan dalam rangka menemukan makna pesan secara komperehensif. Kedua adalah tashawwur, yaitu tahapan pembentukan persepsi yang berasal dari banyak komponen informasi, baik itu informasi yang menguntungkan atau tidak menguntungkan bagi diri seorang muslim. Ketiga adalah iradah, yaitu munculnya hasrat untuk melakukan tindakan yang diprakarsai oleh keutuhan persepsi. Keempat adalah fi'l, yakni realisasi dalam bentuk tindakan. Apabila input dari berbagai komponen yang diperoleh pada tahap awal baik, maka aktualisasi perbuatan akan baik pula, begitupun sebaliknya. ${ }^{29}$

Ranah definisi yang efektif disini menurut Tubbs dalam Usman adalah keberhasilan dalam menyentuh faktor-faktor psikis manusia. Faktor tersebut selanjutnya akan menciptakan lima hal, yaitu pemahaman, kesenangan, reformasi sikap, koneksi komunal yang baik dan tindakan yang ma'ruf.30 Peran yang transformatif ini tidak bisa diperoleh apabila penyampaian dakwah masih berkutat pada kepentingan-kepentingan tendensius. Hadis dalam hal ini menemui titik problematika yang kompleks, jika hadis ditempatkan sebagai teks yang proporsional dalam merespon suatu fenomena, maka hadis tersebut relevan dan solutif. Namun apabila hadis digunakan sebagai tumpangan kepentingan sementara oleh oknum tertentu, maka alokasi hadis sebagai

${ }^{27}$ Yedi Purwanto, Muhamad Taufik, and Asep Wawan Jatnika, "Peran Teknologi Informasi Dalam Perkembangan Dakwah Mahasiswa," Jurnal Sosioteknologi 16, no. 1 (2017): 96.

${ }^{28 N u r r a h m i ~ a n d ~ F a r a b u a n a, ~ " E f e k t i v i t a s ~ D a k w a h ~ M e l a l u i ~ I n s t a g r a m, " ~} 3$.

${ }^{29} \mathrm{H}$. Harjani Hefni, "Pengaruh Informasi Dalam Membentuk Persepsi (Perspektif Al-Quran Dan Hadits)," Jurnal Al-Hikmah: Jurnal Dakwah 8, no. 1 (2014): 38, https://doi.org/10.24260/al-hikmah.v8i1.68.

${ }^{30}$ Fadly Usman, "Efektivitas Penggunaan Media Online Sebagai Sarana Dakwah," Al-Tsiqoh: Jurnal Ekonomi Dan Dakwah Islam 1, no. 1 (2016): 3. 
pedoman hidup tidak akan optimal di masyarakat, dan akan memunculkan stigma negatif terhadap Islam. ${ }^{31}$

Selaras dengan penelitian ini, Entman melalui kacamata framing-nya memberikan prosedur dalam membongkar suatu konten sehingga dapat diketahui bagaimana konten tersebut dikemas. Hal ini secara praktis dapat memberikan sebuah definisi, pemaparan peristiwa dan konteks yang dinamis, hingga menawarkan argumentasi naratif yang berguna sebagai perbaikan dalam rangka evaluasi. ${ }^{22}$ Penggunaan konsep Desain Komunikasi Visual (DKV) pun turut mengambil peran dalam aktivitas dakwah masa kini. Pemanfaatan DKV memberikan penguatan dalam aspek visual secara komplit seperti tipografi, ilustrasi, warna, garis, komposisi, layout dan sebagainya. Sehingga kolaborasi dari beberapa komponen tersebut akan membentuk sebuah sinergi konten yang tidak biasa dan mampu diserap oleh multi pengguna media sosial yang heterogen. ${ }^{33}$ Selaras dengan Aziz, ia menyatakan bahwa dakwah pun harus bersifat orisinil, universal, mudah, kredibel, rasional dan membawa maslahat agar suksesi dakwah dapat terlaksana dengan baik. Seorang content creator (da'i) juga selayaknya turut memahami karakteristik dakwah yang disampaikan. Hal itu dapat dikelola apabila seorang da'i mampu mengemas pesan dakwahnya dengan baik, lugas, menarik dan tidak bertele-tele. ${ }^{34}$

Pada konteks pengelolaan perusahaan dakwah yang besar, perlu diterapkan suatu metode dan prosedur khusus untuk mengawetkan prosesi dakwah kepada umat. Pertama, Planning atau perencanaan menjadi tahap awal untuk merancang sebuah proyek besar apabila suksesi dakwah ingin diraih dengan capaian yang optimal. Planning dapat dicanangkan pada segala aspek dalam instrumen-instrumen pelaksanaan proyek, baik yang bersifat esensial maupun teknis. Perencanaan untuk branding dalam hal ini juga turut dalam upaya pengenalan identitas kepada publik. Kedua, organizingdan controllingatau pengorganisasian dan kontrol dalam pengelolaan elemen-elemen perusahaan dakwah berbasis digital mutlak diperlukan. Sama halnya dengan perusahaan konvensional, perusahaan dakwah juga perlu melakukan pengorganisasian maupun kontrol pada bagian-bagian yang menjadi motor bergeraknya suatu perusahaan, seperti aspek keuangan, strategi pemasaran dan lain

${ }^{31}$ Muhamad Aiman Kamarudin et al., "Media Sosial Dan Dakwah Menurut Islam" (Kertas Kerja Dibentangkan di Seminar Sains Teknologi dan Manusia, 2019), 136-37.

32Mulyana, Analisis Framing: Konstruksi, Ideologi, Dan Politik Media, 187.

${ }^{33}$ Rakhmat Supriyono, "Desain Komunikasi Visual Teori Dan Aplikasi," Yogyakarta: Andi, 2010, 67.

${ }^{34}$ Moh. Ali Aziz, Ilmu Dakwah (Jakarta: Kencana Prenada Media Group, 2009), 342. 
sebagainya. Ketiga, Actuating atau pengaktualisasian pada konsep-konsep makro sebuah perusahaan harus dilakukan. Pada tahap ini, garis-garis besar yang sudah direncanakan oleh perusahaan, sesegera mungkin dilakukan pelaksanaan sesuai target yang ingin dicapai. Keempat, evaluating atau evaluasi merupakan tahap konklusi dalam perusahaan dalam merumuskan gerak langkah selanjutnya dengan meninjau hasil dan capaian yang telah diperoleh.

Dalam hal ini, dua akun yang menjadi atensi peneliti, yakni @hadispedia dan@pusatkajianhadis, telah sedikit banyak mengimplementasikan kombinasi efektivitas dakwah di atas. Pada akun @hadispedia, penggunaan konten yang variatif memunculkan kemungkinan pada ketertarikan yang lebih tinggi daripada @pusatkajianhadis. Sebab pada@hadispedia, content creator menyuguhkan konten yang memuat audio visual (video), berbeda dengan (a) pusatkajianhadis yang tersegmentasi hanya pada konten visual (foto). Sehingga menurut Riyana, konten dengan audio visual menghadirkan sebuah kejelasan makna, keakraban, representasi isi hingga visualisasi tujuan cenderung tersampaikan dengan mudah. ${ }^{35}$ Secara global, konsep yang diterapkan oleh kedua akun tersebut, maupun akun-akun dakwah hadis lainnya telah merepresentasikan wajah e-dakwah masa kini. Tentu fakta ini meruntuhkan stigma bahwa hadis tidak bisa beradaptasi dengan kemajuan modern. Kehadiran model dakwah hadis seperti ini merupakan implementasi terhadap konsep al-Islamu Shalih li Kulli Zaman wa al-Makan (Islam yang adaptif terhadap setiap masa dan tempat).

\section{Kesimpulan}

Metode dakwah yang ditempuh dengan memanfaatkan piranti teknologi dapat menghasilkan efektivitas dakwah yang lebih optimal daripada metode dakwah konvensional sebelumnya. Penggunaan dalam melakukan pembingkaian (framing) terhadap muatan dakwah juga secara inklusif membentuk sebuah sudut pandang yang berbeda dalam melihat konten islam, khususnya hadis. Dalam hal ini, hadis tidak lagi dianaktirikan sebagai teks kuno yang tidak aktual terhadap konteks masa kini, melainkan sebagai sarana yang dapat diakses publik untuk mengetahui narasi-narasi islam. Implementasi ini secara konkrit telah tercermin pada akun-akun dakwah dalam media sosial berbasis daring, khususnya Instagram, yakni pada akun@hadispedia dan@pusatkajianhadis. Sebagai moda perusahaan dakwah yang telah diakses oleh banyak followers, keduanya saat ini telah membuat dakwah begitu efektif untuk menciptakan transformasi akhlak melalui konten islam yang berhasil diserap oleh umat muslim maupun konsumen media secara umum. Alhasil, model dakwah seperti ini perlu menjadi sebuah referensi baru dalam membuat metode dakwah yang efektif dan efisien.

${ }^{35}$ Nurrahmi and Farabuana, "Efektivitas Dakwah Melalui Instagram,” 13. 


\section{Daftar Pustaka}

\section{Buku dan Jurnal}

Annisa, Nur. "Keefektifan Dakwah Melalui Media Sosial Di Masa Pandemi," 2020.

Atmadja, Xena Levina. “Analisis Framing Terhadap Pemberitaan Sosok Basuki Tjahaja Purnama (Ahok) Di Media Online.” Jurnal E-Komunikasi 2, no. 1 (2014).

Aziz, Moh. Ali. Ilmu Dakwah. Jakarta: Kencana Prenada Media Group, 2009.

Entman, Robert N. "Framing: Toward Clarification of a Fractured Paradigm," 1993.

Foust, Jim. Online Journalism: Principles and Practices of News for the Web. Taylor \& Francis, 2017.

Hallahan, Kirk. "Seven Models of Framing: Implications for Public Relations." Journal of Public Relations Research 11, no. 3 (1999): 205-42.

Hapsari, Twediana Budi. "Audiens Framing: Peluang Baru Dalam Penelitian Audiens." Jurnal Aspikom 1, no. 6 (2017): 485-502.

Hefni, H. Harjani. "Pengaruh Informasi Dalam Membentuk Persepsi (Perspektif Al-Quran Dan Hadits)." Jurnal Al-Hikmab: Jurnal Dakwah 8, no. 1 (2014). https://doi.org/10.24260/al-hikmah.v8i1.68.

Kamarudin, Kamarudin. "Dakwah Dan Problematika Studi Hadis." Al-Mishbah: Jurnal Imu Dakwah Dan Komunikasi 9, no. 1 (2013): 133-54.

Kamarudin, Muhamad Aiman, Mustafa Kamal, Muhamad Syakir, and Jimain Safar. "Media Sosial Dan Dakwah Menurut Islam." Kertas Kerja Dibentangkan di Seminar Sains Teknologi dan Manusia, 2019.

Mulyana, DR Deddy. Analisis Framing: Konstruksi, Ideologi, Dan Politik Media. Lkis Pelangi Aksara, 2002.

Mustika, Rieka. "Analisis Framing Pemberitaan Media Online Mengenai Kasus Pedofilia Di Akun Facebook." Jurnal Penelitian Komunikasi 20, no. 2 (2017).

Nurrahmi, Febri, and Puteri Farabuana. "Efektivitas Dakwah Melalui Instagram." Nyimak: Journal of Communication 4, no. 1 (2020): 1-16.

Omar, Faradillah Iqmar, Hazlin Falina Rosli, Nurzakira Afnee Zakaria, and Nuraina Nabila Dundai Abdullah. "Hubungan Penggunaan Media Sosial Dan Penerimaan Mesej Dakwah." In Proceeding of the 2nd International Conference on Management and Muamalah, 181-91, 2015.

Pratiwi, Ardhina. "Konstruksi Realitas Dan Media Massa (Analisis Framing Pemberitaan LGBT Di Republika Dan BBC News Model Robert N. Entman)." Thaqafiyyat: Jurnal Bahasa, Peradaban Dan Informasi Islam 19, no. 1 (2018): 50-71.

Primasari, Winda, and Yudha Asmara Dwi Aksa. "Framing Pesan Dakwah Di Media Sosial." Jurnal Komunikasi Islam 7, no. 1 (2017): 66-86.

Purwanto, Yedi, Muhamad Taufik, and Asep Wawan Jatnika. "Peran Teknologi Informasi Dalam Perkembangan Dakwah Mahasiswa." Jurnal Sosioteknologi 16, no. 1 (2017): 94-109. 
Romli, Asep Syamsul M. Jurnalistik Online: Panduan Mengelola Media Online. Nuansa Cendekia, 2018.

Supriyono, Rakhmat. "Desain Komunikasi Visual Teori Dan Aplikasi." Yogyakarta: Andi, 2010.

Suriani, Julis. "Komunikasi Dakwah Di Era Cyber.” An-Nida' 42, no. 1 (2018): 30-51.

Usman, Fadly. "Efektivitas Penggunaan Media Online Sebagai Sarana Dakwah." Al-Tsiqoh: Jurnal Ekonomi Dan Dakwah Islam 1, no. 1 (2016): $1-8$.

\section{Media Daring}

"\#AyoNgajiHadis on Instagram: 'Bener g Nih, Pemimpin Yang Nyusahin Rakyatnya Didoain Oleh Rasul Langsung? .. Yuk Kita Tela'ah Hadisnya, Bagaimana Sebenarnya Maksud Dari...." Accessed January 11, 2021. https://www.instagram.com/p/CHuiWZCDkRV/.

“\#AyoNgajiHadis on Instagram: 'Diantara Ajaran Agama Islam Di Saat Kesulitan Atau Membutuhkan Sesuatu, Sebenarnya Adalah Kesadaran Kembali Bahwa Segala Yang Ditakdirkan...”" Accessed January 18, 2021. https://www.instagram.com/p/CHfIFvAD9ru/.

“\#AyoNgajiHadis on Instagram: 'Shalat Adalah Ibadah Yang Agung. Ia Menjadi Perintah Spesial Allah Swt. Yang Harus Diambil Nabi Saw. Langsung Ke Langit Melalui Peristiwa....” Accessed January 11, 2021. https://www.instagram.com/p/CF_5jQXsRJ6/.

“\#AyoNgajiHadis’s (@hadispedia) Instagram Profile • 317 Photos and Videos.” Accessed January 9, 2021. https://www.instagram.com/hadispedia/.

"Pusat Kajian Hadis on Instagram: '. . *Musibah Menghapus Dosa*

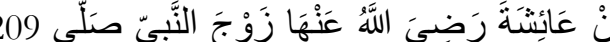

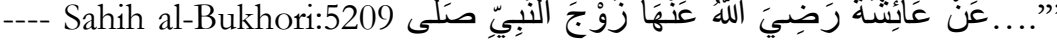
Accessed January 11, 2021. https://www.instagram.com/p/CIOEHk2s-NQ/.

"Pusat Kajian Hadis (@pusatkajianhadis) • Instagram Photos and Videos." Accessed January 11, 2021. https://www.instagram.com/pusatkajianhadis/. 